\title{
Vulnerable atherosclerotic plaque - a review of current concepts and advanced imaging
}

\author{
Miloslav Spacek ${ }^{\mathrm{a}}$, David Zemanek ${ }^{\mathrm{b}}$, Martin Hutyra ${ }^{\mathrm{a}}$, Martin Sluka ${ }^{\mathrm{a}}$, Milos Taborsky ${ }^{\mathrm{a}}$
}

\begin{abstract}
Atherosclerosis is the most common cause of both carotid and coronary steno-occlusive disease. Rupture of an atherosclerotic plaque may lead to the formation of an overlying thrombosis resulting in complete arterial occlusion or downstream embolism. Clinically, this may manifest as a stroke or acute myocardial infarction, the overall leading causes of mortality and disability in developed countries. In this article, we summarize current concepts of the development of vulnerable plaque and provide an overview of commonly used imaging methods that may suggest/indicate atherosclerotic plaque vulnerability.
\end{abstract}

Key words: atherosclerosis, vulnerable plaque, carotid artery, coronary artery, imaging

Received: September 18, 2017; Accepted with revision: February 6, 2018; Available online: February 21, 2018

https://doi.org/10.5507/bp.2018.004

${ }^{a}$ Department of Internal Medicine I - Cardiology, Faculty of Medicine and Dentistry, Palacky University Olomouc and University Hospital Olomouc, Olomouc, Czech Republic

${ }^{b} 2^{\text {nd }}$ Department of Internal Medicine - Department of Cardiovascular Medicine, First Faculty of Medicine, Charles University in Prague and General University Hospital in Prague, Czech Republic

Corresponding author: David Zemanek, e-mail: david.zemanek@lf1.cuni.cz

\section{INTRODUCTION}

Atherosclerotic diseases, including stroke and acute coronary syndromes, are the leading causes of both mortality and disability in industrialized countries ${ }^{1}$. Although atherosclerosis itself is a relatively benign process of slow (lifelong) but gradual vascular remodeling, it may be abruptly complicated by rupture or erosion of an atherosclerotic plaque with an overlying thrombosis precipitating acute ischemic event. Currently, two different approaches are used for the identification and management of patients at risk of acute vascular events: 1) in those with stable coronary syndromes, the extent of ischemia is evaluated and in the case of large "area-inrisk" ,revascularization is considered, 2) in "event-naive" subjects, identification of the risk of future events mainly relies on the estimations derived from the cumulation of "classic" risk factors. These may be calculated using the Systematic Coronary Risk Evaluation ("SCORE") system or the Framingham risk equation ${ }^{2,3}$. Nevertheless, because acute vascular events occur (in absolute numbers) more commonly in non-high-risk patients (due simply to their significantly larger representation in the population) and considering that the majority of acute vascular events are caused by rupture or erosion of hemodynamically non-significant atherosclerotic plaques ${ }^{4}$ (largely outnumbering flow-limiting stenoses), one is not surprised that there is constant effort in the search for more individualized approaches to risk stratification. During the past decade, development of new tools allowing us to better understand the atherosclerotic process as well as to more precisely characterize the structure and potential vulnerability of the plaque, has been the focus of considerable attention ${ }^{5}$.

\section{INITIATION OF ATHEROSCLEROTIC PLAQUE}

Few human diseases have a longer "incubation" period than atherosclerosis typically manifesting without warning after several decades. Accelerated by poor diet and diminished physical activity, it has become epidemic in developed as well as "westernized" countries. Indeed, intimal lesions can be found in many such persons, even in their early decades of life. Over the last century, there has been a remarkable evolution in understanding the pathogenesis of atherosclerosis including detailed description of processes within the vascular wall, providing important concepts for future research.

The layer of endothelial cells constitutes the crucial contact surface with blood and is one of the only surfaces, either natural or artificial, that can maintain blood in a liquid state during protracted contact. The second major cell type, smooth muscle cells localized in the arterial media, has many important functions such as to contract and relax in order to control blood flow. Interestingly, with aging, human arteries develop a more complex (thicker) intima despite the absence of atherosclerosis.

Currently, atherosclerosis is viewed as an inflammatory disease, while experiments with dietary modulation performed in the early 20th century clearly proved cholesterol plays a key role in promoting atherosclerosis ${ }^{6}$. On initiation of an atherogenic diet (rich in cholesterol and saturated fats), small lipoprotein particles accumulate in the intima, particularly at sites of hemodynamic strain ${ }^{7,8}$. Susceptible to oxidative stress, they undergo chemical modification that initiates the attraction of leukocytes,- a process orchestrated by leukocyte adhesion molecules. Leukocytes begin to adhere to arterial endothelium, penetrate the endothelial cells and scavenge lipid particles, 
becoming foam cells ${ }^{9}$. The foam cells not only serve as a reservoir for excess lipid, they are a rich source of inflammatory mediators, promoting inflammation and progression of the lesion ${ }^{10,11}$. While the early events in the atheroma involve primarily altered endothelial function and consequently recruitment and accumulation of leukocytes, the evolution into more complex plaques also involves smooth muscle cells.

\section{PROGRESSION OF ATHEROSCLEROTIC PLAQUE}

If the stimulus for atherogenesis is amplified, foam cells disintegrate and release lipid into the extracellular space, forming a mostly acellular lipid pool ${ }^{12,13}$. At the same time, activated smooth muscle cells migrate into the intimal layer and proliferate, strikingly increasing its ability to produce collagen and repair and maintain the fibrous cap ${ }^{14}$. With the thickening of the plaque, its deeper layers may become hypoxic, triggering angiogenesis and micro vessel proliferation from the adventitial vasa vasorum. These neovessels are, however, immature, fragile and prone to bleeding that yields rapid changes in plaque size and composition and may promote the transition from a stable into an unstable lesion ${ }^{15}$. This detrimental process of plaque destabilization is also supported by the activation of matrix metalloproteinases and inflammation-activated apoptosis or necrosis of the surrounding cells and aggravated by hemorrhage of erythrocytes with cholesterol-rich membranes, particularly in hypercholesterolemic patients ${ }^{16,17}$.

It is now evident that plaque progression is not a gradual process but rather a series of episodes of clinical injury and healing. This concept is supported by pathological findings of distinct plaque laminations clearly demonstrating stepwise plaque progression. It has also become clear that these "crises of inflammation" are dispersed over the arterial tree suggesting the diffuse effect of risk factors ${ }^{18}$. In the case of an acute event, a thrombogenic cascade is activated due to exposure of highly thrombogenic fatty core components leading to the development of an acute occlusive thrombus. If, instead of plaque rupture, erosion occurs, the process of occlusion may be counterbalanced by the fibrinolytic system. The end result may be either thrombus progression with the risk of occlusion, distal embolization or thrombus regression and healing that may again be evidenced as plaque lamination. Most importantly, several plaque characteristics are suggested to portend the risk of instability while high dose statin therapy has been shown to stabilize plaque volume ${ }^{19}$.

\section{VULNERABLE PLAQUE VS. MYOCARDIUM AT RISK}

Coronary arteriography, first performed by Mason Sones in 1959, was a pioneering method in the evaluation of the extent of coronary artery disease. It soon became the gold standard and is currently the most widely used invasive procedure in cardiovascular medicine. Its primary goal is to identify and localize significant coronary stenosis suggesting that the more proximal and diffuse the disease, the more pronounced is the benefit from revascularization ${ }^{20}$. However, its specificity in determining the significance of coronary artery disease in patients with borderline stenosis has been repeatedly questioned $^{21}$. Fractional flow reserve has emerged as an invasive method for evaluating the hemodynamic relevance of coronary stenosis by means of measuring the relative poststenotic pressure drop during maximal coronary vasodilation. Currently, it is considered the most direct way for assessing the hemodynamic significance of individual coronary lesions and is recommended in all patients with borderline stenosis without non-invasive measurement of the extent of ischemia. Similarly, carotid arteriography is considered the gold standard in evaluating the extent of atherosclerotic carotid artery disease. Although it has been repeatedly shown that the significance of carotid artery stenosis is related to the risk of early recurrence of ischemic stroke $\mathrm{k}^{22,23}$, its predictive value of major events in asymptomatic patients is low ${ }^{24,25}$. This, however, may be improved by the measurement of cerebrovascular reserve ( similarly to coronary reserve) such as with transcranial Doppler ultrasound ${ }^{26}$.

It may thus be simplified, that both coronary and carotid arteriography in stable patients can identify high-risk territory, but it provides little information about the actual risk of plaque destabilization. It is thus believed that the diagnostic accuracy may be improved by evaluating the vulnerability of the atherosclerotic plaque. Moreover, knowledge of the composition of the vessel wall and identification of "hot spots" within the vascular territory is attractive for interventional cardiologists since it could allow optimizing percutaneous interventions such as avoiding the "hot lesion" being only partially covered or even crushed by the edge of a stent.

\section{NON-INVASIVE PLAQUE IMAGING}

Multidetector CT (MDCT) angiography has emerged as the leading platform for non-invasive plaque imaging due to its high speed and resolution. Current generation 320-slice systems can image the entire heart within a single ultrafast rotation at sub-millimeter ${ }^{27}$ resolution and offers high-quality images in both carotid and coronary territory (Fig. 1). Besides detecting lumen stenosis, it provides an estimation of plaque volume. The latter has been hypothesized to even better reflect disease severity $^{28,29}$. In addition, it may help in detecting some of the features associated with plaque vulnerability, such as: 1) positive vessel remodeling (dilation of the vessel wall to maintain sufficient lumen diameter), 2) presence of spotty calcifications and 3) lower plaque density - lower suggests a more lipid core or even plaque hemorrhage ${ }^{29-31}$ (Table 1). Whenever identified in patients with atherosclerotic risk factors, cumulation of these features have been shown to predict the occurrence of subsequent acute coronary syndrome ${ }^{31}$. On the other hand, the presence of solid calcium confers stability, resulting in protection 
Table 1. Classification of carotid plaque based on Haunsfield units.

\begin{tabular}{lc}
\hline Fatty* & $<60 \mathrm{HU}$ \\
Mixed & $60-130 \mathrm{HU}$ \\
Calcified & $>130 \mathrm{HU}$ \\
\hline
\end{tabular}

* Very low HU value $(<0 \mathrm{HU})$ associated with the presence of intraplaque hemorrhage

HU - Haunsfield units

against biomechanical stress while studies with carotid stenting have shown that treating heavily calcified and particularly circumferential plaques, portend the risk of fragmentations and distal embolization ${ }^{32}$. Nevertheless, MDCT is suboptimal in identifying thin fibrous caps due to halo or edge blur effect and its major worrying limitation is radiation exposure ${ }^{33}$. This aside, MDCT currently represents the first-line non-invasive method in the search for vulnerable plaques.

Magnetic resonance imaging (MRI) can provide an image of the biological characteristics of tissue (such as water, lipid and fibrous content) using different contrast weightings. However, due to its low spatial resolution, it is best suited for large, static arteries such as carotids (though MRI is improved using dedicated surface coils) while coronary arteries are difficult to image owing to their small dimension and continuous motion ${ }^{34}$. Its best potential lies in its ability to estimate the thickness of the fibrous cap and the presence of intraplaque hemorrhage. Thick, likely stable, fibrous caps appear as a juxtaluminal band of low signal on time-of-flight images, whereas in plaques with a thin fibrous cap, the dark juxtaluminal band is absent ${ }^{35}$. When a fibrous cap ruptures, the absence of a dark band is accompanied by the presence of a bright gray region adjacent to the lumen, corresponding to the plaque hemorrhage and/or mural thrombus ${ }^{36}$. Intraplaque hemorrhage is currently considered a high-risk for plaque instability and MRI is not only able to detect the presence

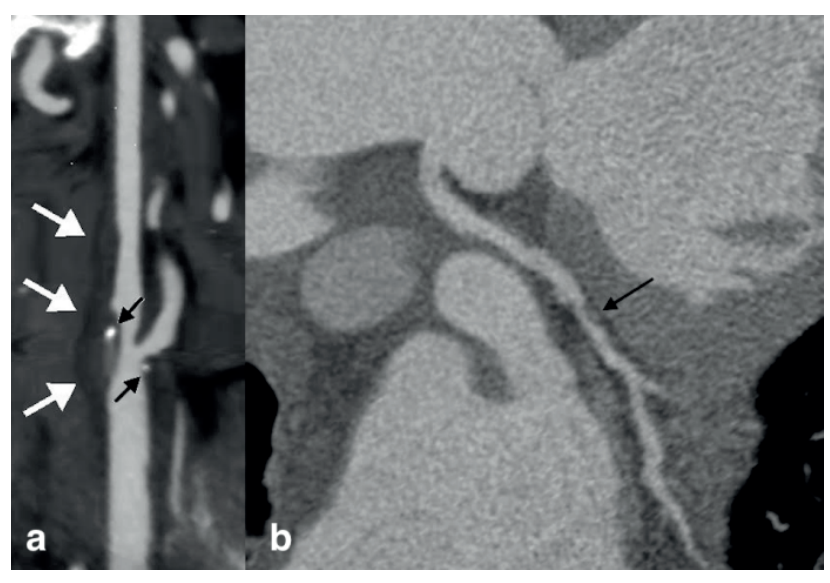

Fig. 1. a) CT angiography of carotid artery: stretched multiplanar reconstruction showing high-volume low-density (white arrows) plaque with minimal calcification (black arrows). b) CT angiography of coronary artery: curved multiplanar reconstruction showing low-density plaque with spotty calcification (black arrow) causing significant lumen narrowing. Courtesy of Dr. Tudos Z. Dpt. of Radiology, Faculty of Medicine and Dentistry, Palacky University Olomouc and University Hospital Olomouc, Olomouc, Czech Republic.

of plaque hemorrhage (based on the presence of metahemoglobin or hemosiderin), it is also able to age plaque hemorrhage using specific imaging techniques ${ }^{37}$.

Carotid ultrasonography (Fig. 2a) is a first-line method for quantifying the degree of stenosis due to its low cost. It may, however, also be used to estimate plaque vulnerability based on the plaque surface and composition ${ }^{38,39}$. First, smooth plaques without any sign of ulceration or irregularity indicate a stable plaque while irregularities and particularly frank ulcerations significantly increase the risk of cerebrovascular events as demonstrated by the NASCET study ${ }^{40}$. Second, Geroulakos et al ${ }^{41}$ classified plaques into five types based on echogenicity with types 1 and 2 (both predominantly anechogenic) similar to CT
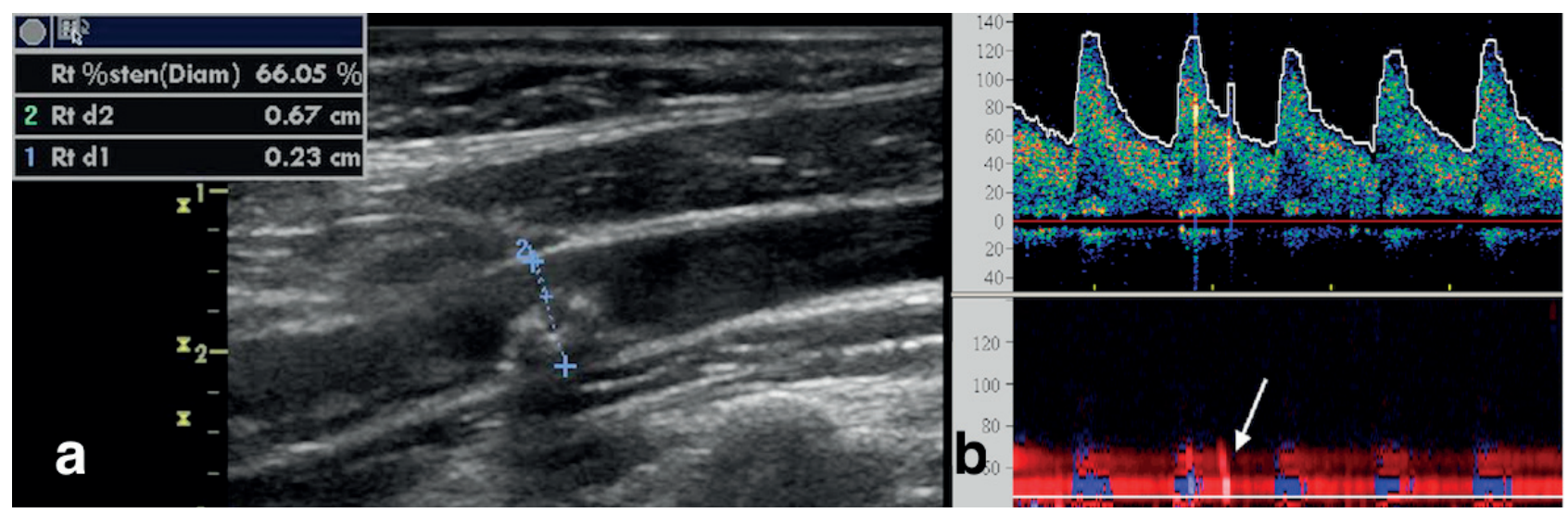

Fig. 2. a) Carotid ultrasonography: longitudinal section of internal carotid artery showing atherosclerotic plaque with irregular surface. Courtesy of Dr. Kovacik F. Department of Internal Medicine I - Cardiology, Faculty of Medicine and Dentistry, Palacky University Olomouc and University Hospital Olomouc, Olomouc, Czech Republic. b) Transcranial doppler ultrasound - view through temporal bone window: multi-gate color-coded display (bottom) showing typical HITSignal (arrow) traveling superficially through middle cerebral artery (color-coded flow at a depth of 70-45mm). Corresponding single-gate trace (top) from a depth of approx. $45-50 \mathrm{~mm}$. 
fatty plaques. Third, using micro-bubble contrast, it is possible to estimate the degree of neovascularization, linked to the degree of inflammation, based on plaque contrast enhancement ${ }^{42}$. This technique is similar to gadolinium based contrast enhancement that may be used to estimate neovascularization in MRI (ref. ${ }^{43,44}$ ). Transcranial Doppler ultrasound is another portable and low cost sonographic method used primarily to evaluate flow within cerebral vasculature. It is also able to detect high intensity transient signals (Fig. 2b), which correlate with solid particles travelling within the artery. Importantly, it has been demonstrated that detection of such signals is linked to increase in risk of a cerebrovascular event up to 4 times and thus may indirectly reflect the plaque vulnerability ${ }^{45,46}$.

Nuclear imaging modalities are intrinsically designed to image systemic disorders such as atherosclerosis due to their whole-body and targeted-imaging capabilities. For several reasons, such as increased spatial resolution (4-5mm compared to $1-1.6 \mathrm{~cm}$ in SPECT), positron emission tomography (PET) has been used in most studies on nuclear imaging in atherosclerosis. Labelled fluorodeoxyglucose (FDG) is currently the most validated tracer for imaging plaque inflammation. In particular, FDG progressively accumulates in metabolically active cells such as activated macrophages. Whereas imaging of coronary arteries is challenging, owing mainly to intense tracer uptake of adjacent myocardium, high FDG uptake in carotid plaques has been shown to correlate with macrophage accumulation $^{47,48}$. Moreover, carotid FDG PET is highly reproducible and appears to be able to reflect therapeutic interventions, suggesting a possible role in treatment monitoring ${ }^{49}$. Finally, apart from glucose uptake, numerous other metabolic and signalling pathways associated with vulnerable plaque (such as labelled low density lipoproteins, matrix metalloproteinase inhibitors ${ }^{50}$, chemotactic proteins and others) may be targeted with nuclear imaging. Such highly investigational targeted molecular imaging is, however, no longer restricted to PET but is being investigated in other modalities, such as MRI as well as MDCT using dedicated agents.

\section{INTRAVASCULAR PLAQUE IMAGING}

Intravascular ultrasound (IVUS) is one of the first techniques used to assess plaque morphology and is currently widely used in routine clinical practice (Fig. 3). IVUS employs miniaturized ultrasound transducers (20$45 \mathrm{MHz}$ ) to obtain real-time cross-sectional tomographic images perpendicular to the long axis during pull-back. The intensity of the backscatter signal is processed in gray scale with a spatial resolution of $150 \mu \mathrm{m}$, that determines both the lumen stenosis and several signs of plaque vulnerability ${ }^{51-53}$, notably the presence of an echolucent core (probably representing a lipid-rich core), positive vessel wall remodeling, plaque length and spotty calcifications (IVUS defined as an arc of calcified plaque that encompasses less than 1/4 of the cross-sectional image). On the other hand, it does not permit identification of the cap thickness that is below the spatial resolution of IVUS systems. While grayscale IVUS can effectively differentiate calcified from non-calcified plaques, it cannot accurately determine non-calcified plaque tissue composition due to the limitations of post-processing. However, spectral analysis of the IVUS backscatter signal before demodulation and scan conversion can overcome some of these limitations and has given rise to a virtual histology IVUS (VH-IVUS) (Fig. 3). With VH-IVUS, plaque components are usually categorized into 4 types: fibrous, fibrofatty, calcified necrotic and calcified which are displayed as a color-coded map ${ }^{54,55}$. Moreover, it can further differentiate thin cap fibroatheroma (TCFA) defined as a necrotic core

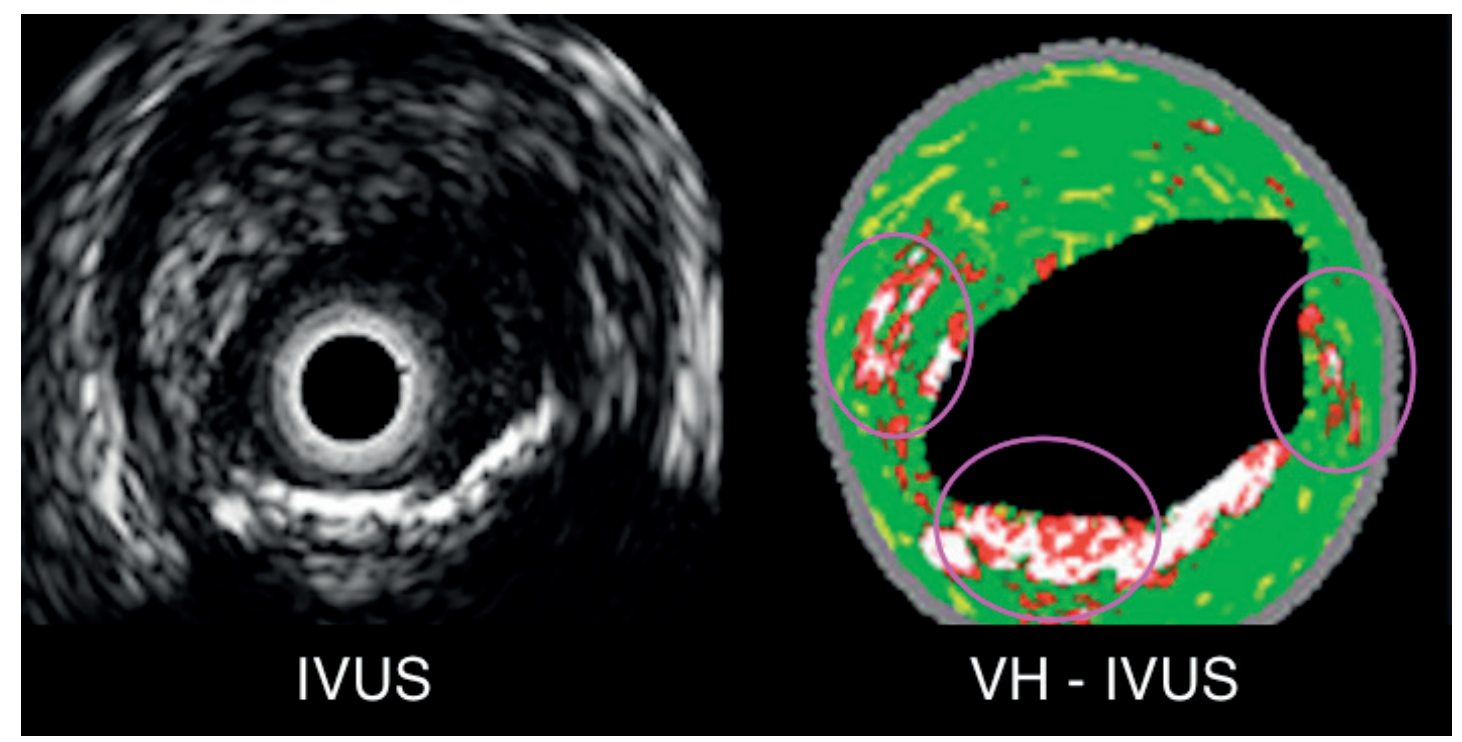

Fig. 3. a) IVUS (left) and corresponding Virtual Histology IVUS (right) cross-sectional view of atherosclerotic plaque with areas of necrotic content cumulation (red color/circled). Courtesy of Dr. Richter D. Department of Internal Medicine I - Cardiology, Faculty of Medicine and Dentistry, Palacky University Olomouc and University Hospital Olomouc, Olomouc, Czech Republic. 


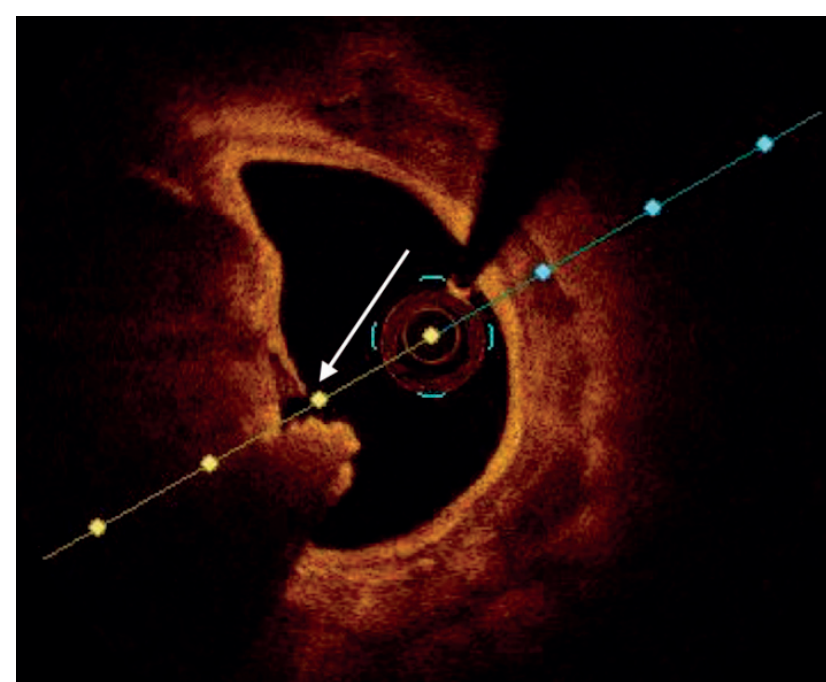

Fig. 4. OCT cross sectional view of ruptured atherosclerotic plaque with visible intimal flap and mixed thrombus (arrow). Note superior resolution compared to IVUS. Courtesy of Dr. Kovarnik T. PhD. 2nd Department of Internal Medicine, Department of Cardiovascular Medicine, First Faculty of Medicine, Charles University in Prague and General University Hospital in Prague, Prague, Czech Republic.

extending into the lumen surface. The diagnostic accuracy of VH-IVUS was validated against histology and has shown a sensitivity, specificity and predictive accuracy for detecting a necrotic core of $67.3 \%, 92.9 \%$ and $88.3 \%$, respectively ${ }^{54,56}$. In the landmark PROSPECT trial ${ }^{57}$, which evaluated the natural history of all $>30 \%$ stenosed coronary plaques identified by 3-vessel grayscale and VH-IVUS imaging in acute coronary syndrome patients, the presence of TCFAs assessed by VH-IVUS correlated well with subsequent risk of major adverse cardiac events (hazard ratio 3.35) at a median follow-up of 3.4 years, however, the predictive accuracy was low. The authors acknowledged that of 595 TCFAs, only 26 became the culprit site of the subsequent event. Interestingly, in a subgroup analysis, patients with higher residual atherosclerotic disease (more necrotic core and TCFAs) had significantly higher nonculprit events compared to those without ( $P=0.0001)$, supporting the concept that greater residual coronary disease portends greater future risk $^{58}$.

Optical coherency tomography (OCT) uses reflected near-infrared light to obtain unsurpassed high-resolution images $^{59}$ (Table 2). Due to attenuation of the signal by blood, visualization is performed through brisk saline or contrast flushing, promoted by very rapid data acquisition (maximal pullback speed up to $40 \mathrm{~mm} / \mathrm{sec}$ ). Its superb image resolution allows accurate recognition of features such as plaque rupture or thrombi (Fig. 4), cap thickness (considered thin if $\leq 65 \mu \mathrm{m}$ ) or even plaque erosion. OCT was also shown to permit quantification of macrophage content in the fibrous cap ${ }^{60}$ and subintimal lipid accumulation. Positively remodeled plaques have been shown to exhibit greater lipid content and thinner fibrous caps ${ }^{61}$. In patients with diabetes, OCT plaque analysis demonstrated greater lipid content, calcification and thrombus
Table 2. Comparison of basic OCT and IVUS features.

\begin{tabular}{lcc}
\hline & $\begin{array}{c}\text { Frequency } \\
\text { domain OCT }\end{array}$ & IVUS \\
\hline Wave length & $1.3 \mu \mathrm{m}$ & $35-80 \mu \mathrm{m}$ \\
Axial resolution & $10-15 \mu \mathrm{m}$ & $150 \mu \mathrm{m}$ \\
Lateral resolution & $40-90 \mu \mathrm{m}$ & $250 \mu \mathrm{m}$ \\
Tissue penetration & $2-3.5 \mathrm{~mm}$ & $7 \mathrm{~mm}$ \\
Field of view & $<10 \mathrm{~mm}$ & $15 \mathrm{~mm}$ \\
Maximal frame rate & $100-200 \mathrm{fps}$ & $30 \mathrm{fps}$ \\
Maximal pullback speed & $20-40 \mathrm{~mm} / \mathrm{s}$ & $1 \mathrm{~mm} / \mathrm{s}$ \\
\hline
\end{tabular}

fps - frames per second

compared to non-diabetic patients consistent with the recognition that diabetic subjects have more complex and diffuse coronary disease ${ }^{62}$. Moreover, those with poorly controlled diabetes had the highest lipid content and thinner fibrous caps. Interestingly, serial OCT imaging has shown increasing thickness of the fibrous cap in stable angina patients following statin therapy ${ }^{63}$. Although OCT seems to provide the most reproducible images, its major drawback is low penetration/field of view and particularly the need for flushes (or even balloon occlusions), which limits its use in larger arteries such as carotids.

Finally, near infrared spectroscopy (NIRS) is a newer clinical intravascular imaging modality that detects and quantifies the presence of lipid within the vessel wall based on the specific absorption pattern of near-infrared light by cholesterol molecules. Since it provides minimal anatomic information, it is mounted on IVUS acquired structural data and presented as a probability map called a "chemogram". The X-axis of the chemogram indicates the pullback position in millimeters and the Y-axis indicates the circumferential position in degrees as though the coronary vessel has been split open along its longitudinal axis. It has been validated against coronary autopsy specimens and proven superior to IVUS alone in the detection of lipid core plaques ${ }^{64}$. While its value in clinical use is currently under investigation in large prospective studies, there have already been reports of testing combined NIRS-OCT probes that may further improve the accuracy of the system ${ }^{65}$.

\section{CONCLUSION}

Atherosclerosis is currently viewed as a dynamic process with episodes of progression and healing, that may or may not clinically manifest depending on many factors. It has become evident that the concept of "ischemic burden", based solely on the degree of stenoses, is oversimplified and there is constant requirement for better patient risk stratification. Particularly over the last decade, understanding of the natural course of atherosclerosis has significantly improved and the concept of "vulnerable plaque (patient)" is proposed. Currently, there are a variety of imaging methods that may aid in the detection of vulnerable plaque, however, the data show that no single parameter can reliably predict future events. The acquisition of 
such additional information also comes with either higher cost, radiation or additional intravascular manipulation. Therefore, albeit the concept of vulnerable plaque appears very attractive and promising in tailoring individual patient therapy, its clinical use is still in its infancy and the essential questions including when and in whom to apply such an investigation still need to be answered.

\section{Search strategy and selection criteria}

We examined studies and articles from various resources (e.g. PubMed, MEDLINE). The search terms used included atherosclerosis, vulnerable plaque, coronary arteries, carotid arteries, non-invasive imaging, intracoronary imaging. Citations from journals with high impact factors were given special weight. Only English language papers were reviewed.

\section{ABBREVIATIONS}

MDCT / CT, multidetector computed tomography; MRI, magnetic resonance imaging; SPECT, single-photon emission computed tomography; PET, positron emission tomography; FDG, fluorodeoxyglucose; IVUS, intravascular ultrasound; VH-IVUS, virtual-histology intravascular ultrasound; TCFA, thin cap fibroatheroma; OCT, optical coherence tomography; NIRS, near infrared spectroscopy.

Author contributions: All authors contributed in literature search and manuscript writing. All authors read and approved the final manuscript.

Conflict of interest statement: None declared.

\section{REFERENCES}

1. Lloyd-Jones D, Adams RJ, Brown TM, Carnethon M, Dai S, De Simone G, Ferguson TB, Ford E, Furie K, Gillespie C, Go A, Greenlund K, Haase N, Hailpern S, Ho PM, Howard V, Kissela B, Kittner S, Lackland D, Lisabeth L, Marelli A, McDermott MM, Meigs J, Mozaffarian D, Mussolino M, Nichol G, Roger VL, Rosamond W, Sacco R, Sorlie P, Stafford R, Thom T, Wasserthiel-Smoller S, Wong ND, Wylie-Rosett J; American Heart Association Statistics Committee and Stroke Statistics Subcommittee. Executive summary: heart disease and stroke statistics-2010 update: a report from the American Heart Association. Circulation 2010;121(7):948-54.

2. Anderson KM, Wilson PW, Odell PM, Kannel WB. An updated coronary risk profile. A statement for health professionals. Circulation 1991;83(1):356-62.

3. Conroy RM, Pyorala K, Fitzgerald AP, Sans S, Menotti A, De Backer G, De Bacquer D, Ducimetiere P, Jousilahti P, Keil U, Njolstad I, Oganov RG, Thomsen T, Tunstall-Pedoe H, Tverdal A, Wedel H, Whincup $P$, Wilhelmsen L, Graham IM; SCORE project group. Estimation of tenyear risk of fatal cardiovascular disease in Europe: the SCORE project. Eur Heart J 2003;24(11):987-1003.

4. Falk E, Shah PK, Fuster V. Coronary plaque disruption. Circulation 1995;92(6):657-71.

5. Celeng C, Takx RA, Ferencik M, Maurovich-Horvat P. Non-invasive and invasive imaging of vulnerable coronary plaque. Trends Cardiovascular Med 2016;26(6):538-47.

6. Humphries SE. Guidelines for the identification and management of patients with familial hypercholesterolemia (FH): are we coming to a consensus? Atheroscler Suppl 2011;12(2):217-20.

7. Skalen K, Gustafsson M, Rydberg EK, Hulten LM, Wiklund O, Innerarity $\mathrm{TL}$, Boren J. Subendothelial retention of atherogenic lipoproteins in early atherosclerosis. Nature 2002;417(6890):750-4.
8. Jufri NF, Mohamedali A, Avolio A, Baker MS. Mechanical stretch: physiological and pathological implications for human vascular endothelial cells. Vasc Cell 2015;7(1):8.

9. Hansson GK. Inflammation, atherosclerosis and coronary artery disease. N Engl J Med 2005;352(16):1685-95.

10. Libby P. Inflammation in atherosclerosis. Arterioscler Thromb Vasc Biol 2012;32(9):2045-51.

11. Andersson J, Libby P, Hansson GK. Adaptive immunity and atherosclerosis. Clin Immunol 2010;134(1):33-46.

12. Saybolt MD, Lilly SM, Patel D, Hamamdzic D, Llano R, Fenning RS, Madden S, Wilensky RL. The vulnerable artery: early and rapid deposition of lipid in coronary arteries is associated with subsequent development of thin-cap fibroatheromas. Eurolntervention 2016;11(14):e1612-8.

13. Janoudi A, Shamoun FE, Kalavakunta JK, Abela GS. Cholesterol crystal induced arterial inflammation and destabilization of atherosclerotic plaque. Eur Heart J. 2016;37(25):1959-67.

14. Libby P. Mechanisms of the acute coronary syndromes and their implications for therapy. N Engl J Med 2013;368(21):2004-13.

15. Moreno PR, Purushothaman KR, Fuster V, Echeverri D, Truszczynska $\mathrm{H}$, Sharma SK, Badimon JJ, O'Connor WN. Plaque neovascularization is increased in ruptured atherosclerotic lesions of human aorta. Implications for plaque vulnerability. Circulation 2004;110(14):20328.

16. Karunakaran D, Geoffrion M, Wei L, Gan W, Richards L, Shangari $P$, DeKemp EM, Beanlands RA, Perisic L, Maegdefessel L, Hedin U, Sad S, Guo L, Kolodgie FD, Virmani R, Ruddy T, Rayner KJ. Targeting macrophage necroptosis for therapeutic and diagnostic interventions in atherosclerosis. Sci Adv 2016;2(7):e1600224.

17. Tuenter A, Selwaness M, Arias Lorza A, Schuurbiers JC, Speelman L, Cibis $M$, van der Lugt $A$, de Bruijne $M$, van der Steen AF, Franco $\mathrm{OH}$, Vernooij MW, Wentzel JJ. High shear stress relates to intraplaque haemorrhage in asymptomatic carotid plaques. Atherosclerosis. 2016;251:348-54.

18. Vergallo R, Ren X, Yonetsu T, Kato K, Uemura S, Yu B, Jia H, Abtahian F, Aguirre AD, Tian J, Hu S, Soeda T, Lee H, McNulty I, Park SJ, Jang Y, Prasad A, Lee S, Zhang S, Porto I, Biasucci LM, Crea F, Jang IK. Pancoronary plaque vulnerability in patients with acute coronary syndrome and ruptured culprit plaque: A 3-vessel optical coherence tomography study. Am Heart J 2014;167(1):59-67.

19. Puri R, Nissen SE, Libby P, Shao M, Ballantyne CM, Barter PJ, Chapman MJ, Erbel R, Raichlen JS, Uno K, Kataoka Y, Nicholls SJ. C-reactive protein, but not low-density lipoprotein cholesterol levels, associate with coronary atheroma regression and cardiovascular events following maximally intensive statin therapy. Circulation 2013;128(22):2395-403.

20. Coronary artery surgery study (CASS): a randomized trial of coronary artery bypass surgery. Survival data. Circulation 1983;68(5):939-50.

21. Tonino PA, De Bruyne B, Pijls NH, Siebert U, Ikeno F, van't Veer M, Klauss V, Manoharan G, Engstrom T, Oldroyd KG, Var Lee PN, MacCarthy PA, Fearon WF; FAME Study Investigators. Fractional flow reserve versus angiography for guiding percutaneous coronary intervention. N Engl J Med 2009;360(3):213-24.

22. North American Symptomatic Carotid Artery Trial Collaborators, Barnett HJM, Taylor DW, Haynes RB, Sackett DL, Peerless SJ, Ferguson GG, Fox AJ, Rankin RN, Hachinski VC, Wiebers DO, Eliasziw M. Beneficial effect of carotid endarterectomy in symptomatic patients with high-grade carotid stenosis. N Engl J Med 1991;325(7):445-53.

23. European Carotid Surgery Trialists' Collaborative Group. MRC European Carotid Surgery Trial: interim results for symptomatic patients with severe (70-99\%) or mild (0-29\%) carotid stenosis. Lancet 1991;337(8752):1235-43.

24. Executive Committee for the Asymptomatic Carotid Atherosclerosis Study. Endarterectomy for asymptomatic carotid artery stenosis. JAMA 1995;273(18):1421-8.

25. Halliday AW, Thomas D, Mansfield A. The Asymptomatic Carotid Surgery Trial (ACST). Rationale and design. Steering Committee. Eur J Vasc Surg 1994;8(6):703-10.

26. Silvestrini $M$, Vernieri F, Pasqualetti $P$, Matteis $M$, Passarelli F, Troisi E, Caltagirone C. Impaired cerebral vasoreactivity and risk of stroke in patients with asymptomatic carotid artery stenosis. JAMA 2000;283(16):2122-7.

27. Small GR, Chow BJW. CT imaging of the vulnerable plaque. Curr Treat Options Cardiovasc Med 2017;19(12):92.

28. Ouhlos M, Flach HZ, de Weert TT, Hendriks JM, van Sambeek MR, 
Dippel DW, Pattynama PM, van der Lugt A. Carotid plaque composition and cerebral infarction: MR imaging study. Am J Neuroradiol 2005;26(5):1044-9.

29. de Weert TT, Ouhlos M, Meijering E, Zondervan PE, Hendriks JM, van Sambeek MR, Dippel DW, van der Lugt A. In vivo characterization and quantication of atherosclerotic carotid plaque components with multi detector computed tomography and histopathological correlation. Arterioscler Thromb Vasc Biol 2006;26(10):2366-72.

30. Hoffman U, Moselewski F, Nieman K, Jang IK, Ferencik M, Rahman AM, Cury RC, Abbara S, Joneidi-Jafari H, Achenbach S, Brady TJ. Noninvasive assessment of plaque morphology and composition in culprit and stable lesions in acute coronary syndrome and stable lesions in stable angina by multi detector computed tomography. J Am Coll Cardiol 2006;47(8):1655-62.

31. Motoyama $S$, Sarai $M$, Harigaya $H$, Anno $H$, Inoue $K$, Hara $T$, Naruse H, Ishii J, Hishida H, Wong ND, Virmani R, Kondo T, Ozaki Y, Narula J. Computed tomographic angiography characteristics of atherosclerotic plaques subsequently resulting in acute coronary syndrome. Am Coll Cardiol 2009;54(1):49-57.

32. Tsutsumi M, Kodama T, Aikawa H, Onizuka M, iko M, Nii K, Hamaguch S, Etou H, Sakamoto K, Inoue R, Nakau H, Kazekawa K. Fragmentation of calcified plaque after carotid artery stenting in heavily calcified circumferential stenosis. Neuroradiology 2010;52(9):831-6.

33. Braunwald E. Noninvasive detection of vulnerable coronary plaques. Locking the barn door before the horse is stolen. J Am Coll Cardiol 2009;54(1):58-59.

34. Teng Z, Brown AJ, Gillard JH. From ultrasonography to high resolution magnetic resonance imaging: towards an optimal management strategy for vulnerable carotid atherosclerotic plaques. EBioMedicine 2016;3:2-3.

35. Hatsukami TS, Ross R, Polissar NL, Yuan C. Visualization of fibrous cap thickness and rupture in human atherosclerotic carotid plaque in vivo with high-resolution magnetic resonance imaging. Circulation 2000;102(9):959-64.

36. Demarco JK, Ota H, Underhill HR, Zhu DC, Reeves MJ, Potchen MJ, Majid A, Collar A, Talsma JA, Potru S, Oikawa M, Dong L, Zhao X, Yarnych VL, Yuan C. MR carotid plaque imaging and contrast-enhanced MR angiography identifies lesions associated with recent ipsilateral thromboembolic symptoms: an in vivo study at 3T. AJNR Am J Neuroradiol 2010;31(8):1395-402.

37. Chu B, Kampschulte A, Ferguson MS, Kerwin WS, Yarnych VL, O'Brien KD, Polissar NL, Hatsukami TS, Yuan C. Hemorrhage in the atherosclerotic carotid plaque: a high resolution MRI study. Stroke 2004;35(5):1079-84.

38. Brinjikji W, Rabinstein AA, Lanzino $G$, Murad MH, Williamson EE, DeMarco JK, Huston J 3rd. Ultrasound characteristics of symptomatic carotid plaques: a systematic review and meta-analysis. Cerebrovasc Dis 2015;40(3-4):165-74.

39. Gupta A, Kesavabhotla K, Baradaran H, Kamel H, Pandya A Giambrone AE, Wright D, Pain KJ, Mtui EE, Suri JS, Sanelli PC, Mushlin AL. Plaque echolucency and stroke risk in asymptomatic carotid stenosis: a systematic review and meta- analysis. Stroke 2015;46(1):91 7.

40. Eliasziw M, Steriler JY, Fox AJ, Hachinski VC, Fergusson GG, Barnett $\mathrm{HJ}$. Significance of plaque ulceration in symptomatic patients with high grade carotid stenosis: North American Symptomatic Carotid Endarterectomy Trial. Stroke 1994;25(2):304-8.

41. Geroulakos G, Ramaswani G, Nicolaides A, James K, Labropoulos N Belcaro G, Holloway M. Characterization of symptomatic and asymptomatic carotid plaques using high resolution real time ultrasound. Br J Surg 1993;80(10):1274-7

42. Staub D, Partovi S, Schinkel AF, Coll B, Uthoff H, Achwanden M, Jaegeer KA, Feinstein SB. Correlation of carotid artery atherosclerotic lesion echogenicity and severity at standard US with intraplaque neovascularization detected at contrast enhanced US. Radiology 2011;258(2):618-26.

43. Millon A, Boussel L, Brevet M, Mathevet JL Canet-Soulas E, Mory C, Scoazec JY, Douek P. Clinical and histological significance of gadolinium enhancement in carotid atherosclerotic plaque. Stroke 2012;43(11):3023-8.

44. Johri AM, Herr JE, Li TY, Yau O, Nambi V. Novel Ultrasound Methods to Investigate Carotid Artery Plaque Vulnerability. J Am Soc Echocardiogr 2017;30(2):139-48.
45. Markus HS, King A, Shipley M, Topakian R, Cullinane M, Reihill S, Bornstein NM, Schaafsma A. Asymptomatic embolisation for prediction of stroke in the Asymptomatic Carotid Emboli Study (ACES): a prospective observational study. Lancet Neurol 2010;9(7):663-71.

46. Spence JD. Transcranial Doppler monitoring for microemboli: a marker of a high-risk carotid plaque. Semin Vasc Surg 2017;30(1):626.

47. Tawakol A, Migrino RQ, Bashian GG, Bedri S, Vermylen D, Cury RC, Yates D, LaMuraglia GM, Furie K, Houser S, Gewirtz H, Muller JE, Brady TJ, Fischman AJ. In vivo 18F-fluorodeoxyglucose positron emission tomography imaging provides a non-invasive measure of carotid plaque inflammation in patients. J Am Coll Cardiol 2006;48(9):181824.

48. Liu J, Kervin WS, Caldwell JH, Fergusson MS, Hippe DS, Alessio AM Martinez-Malo V, Pimentel K, Miyaoka RS, Kohler TR, Hatsukami TS, Yuan C. High-resolution FDG-microPET of carotid atherosclerosis: plaque components underlying enhanced FDG uptake. Int J Cardiovasc Imaging 2016;32(1):145-52.

49. Tahata N, Kai H, Ishibashi M, Nakaur H, Kaida H, Baba K, Hayabuchi $N$, Imaizumi T. Simvastatin attenuates plaque inflammation. Evaluation by fluorodeoxyglucose positron emission tomography. J Am Coll Cardiol 2006;48(9):1825-31.

50. Fujimoto S, Hartung D, Ohshima S, Edwards DS, Zhou J, Yalamanchili P, Azure M, Fujimoto A, Isobe S, Matsumoto Y, Boersma H, Wong N, Yamazaki J, Narula N, Petrov A, Narula J. Molecular imaging of matrix metalloproteinase in atherosclerotic lesions. Resolution with dietary modification and statin therapy. J Am Coll Cardiol 2008;52(23):184757.

51. Yamagishi M, Tereshima M, Awano K, Kijima M, Nakatani S, Daikoku S, Ito K, Yasamura Y, Miyatake K. Morphology of vulnerable coronary plaque: insights from follow-up of patients examined by intravascular ultrasound before an acute coronary syndrome. J Am Coll Cardiol 2000;35(1):106-11.

52. Kotani J, Mintz GS, Castagna MT, Pinnow E, Berzingi CO, Bui AB, Pichard AD, Satler LF, Suddath WO, Waksman R, Laird JR Jr, Kent KM, Weissman NJ. Intravascular ultrasound analysis of infarct-related and non-infarct related arteries in patients who presented with an acute myocardial infarction. Circulation 2003;107(23):2889-93.

53. Ehara S, Kobayashi Y, Yoshiama M, Shimada K, Shimada Y, Fukuda D Nakamura Y, Yamashita H, Yamagishi H, Takeuchi K, Naruko T, Haze K, Becker AE, Yoshikawa J, Ueda M. Spotty calcification typifies the culprit plaque in patients with acute myocardial infarction: an intravascular ultrasound study. Circulation 2004;110(22):3424-9.

54. Nair A, Kuban BD, Tuzcu EM, Schoenhagen P, Nissen SE, Vince DG. Coronary plaque classification with intravascular ultrasound radiofrequency data analysis. Circulation 2002;106(17):2200-6.

55. Mehta SK, McCary JR, Frutkin AD, Dolla WJ, Marso SP. Intravascular ultrasound radiofrequency analysis of coronary atherosclerosis: an emerging technology for the assessment of vulnerable plaque. Eur Heart J 2007;28(11):1283-8.

56. Nasu K, Tsuchikane E, Katoh O, Vince DG, Virmani R, Surmely JF, Murata A, Takeda Y, Ito T, Ehara M, Matsubara T, Tereshima M, Suzuki T. Accuracy of in vivo coronary plaque morphology assessment: a validation study of in vivo virtual histology compared with in vitro histopatology. J Am Coll Cardiol 2006;47(12):2405-12.

57. Stone GW, Maehara A, Lansky AJ, de Bruyne B, Cristae E, Mintz GS Mehran R, McPherson J, Farhat N, Marso SP, Parise H, Templin B, White R, Zhang Z, Serruys PW; PROSPECT Investigators. A prospective natural-history study of coronary atherosclerosis. N Engl J Med 2011;364(21):226-35.

58. McPherson JA, Maehara A, Weisz G, Mintz GS, Cristae E, Mehran R, Foster M, Verheye S, Rabbani L, Xu K, Fahy M, Templin B, Zhang Z, Lansky AJ, de Bruyne B, Serruys PW, Stone GW. Residual plaque burden in patients with acute coronary syndromes after successful percutaneous coronary intervention. JACC Cardiovas Imaging 2012;5(3):S95-S105.

59. Kume T, Uemura S. Current clinical applications of coronary optical coherence tomography. Cardiovasc Interv Ther 2017. doi: 10.1007/ s12928-017-0483-8. [Epub ahead of print].

60. Tearney GJ, Yabushita H, Houser SL, Aretz HT, Jang IK, Schlendorf KH, Kauffman CR, Shishkov M, Halpern EF, Bouma BE. Quantification of macrophages content in atherosclerotic plaques by optical coherence tomography. Circulation 2003;107(1):113-9. 
61. Rathore S, Tereshima M, Matsuo H, Kinoshita Y, Kimura M, Tsuchikane E, Nasu K, Ehara M, Asakura Y, Katoh O, Suzuki T. Association of coronary plaque composition and arterial remodelling: a optical coherence study. Atherosclerosis 2012;221(2):405-15.

62. Kato K, Yonetsu K, Kim SJ, Xing L, Lee H, McNulty I, Yeh RW, Sakhuja R, Zhang S, Uemura S, Yu B, Mizuno K, Jang IK. Comparison of nonculprit coronary plaque characteristics between patients with and without diabetes: a 3-vessel optical coherence tomography study. JACC Cardiovasc Interv 2012;5(11):1150-8.

63. Hattori K, Ozaki Y, Ismail TF, Okumura M, Naruse H, Kan S, Ishikawa M, Kawai T, Ohta M, Kawai H, Hashimoto T, Takagi Y, Ishii J, Serruys
PW, Narula J. Impact of statin therapy on plaque characteristics as assessed by serial OCT, greyscale and integrated backscatter-IVUS. JACC Cardiovasc Imaging 2012;5(2):169-77.

64. Kang SJ, Mintz GS, Pu J, Sum ST, Madden SP, Burke AP, Xu K, Goldstein JA, Stone GW, Muller JE, Virmani R, Maehara A. Combined IVUS and NIRS detection of fibroateheromas: histopatological validation in human coronary arteries. J Am Coll Cardiol Img 2015;8(2):184-94.

65. Fard AM, Vacas-Jacques P, Hamidi E, Wang H, Carruth RW, Gardecki JA, Tearney GJ. Optical coherence tomography - near infrared spectroscopy system and catheter for intravascular imaging. Opt Express 2013;21(25):30849-58. 